\title{
Adjustable Dose Pre-filled Pen Syringe
}

National Cancer Institute

\section{Source}

National Cancer Institute. Adjustable Dose Pre-filled Pen Syringe. NCI Thesaurus. Code C107670.

A syringe with a measured dose of medication that has an apparatus that enables the user to specify the amount of the medication to deliver in an injection. 